\title{
ALTERNATIVE THERAPEUTIC APPROACHES IN THE ERA OF ANTIMICROBIAL RESISTANCE: AN OVERVIEW ${ }^{\dagger}$
}

\author{
T. K. DUTTA ${ }^{1}$ \\ ${ }^{1}$ Department of Veterinary Microbiology, CVSc \& AH, Central Agricultural University, Selesih, Aizawl, \\ Mizoram - 796 014, India
}

\begin{abstract}
The problem of antimicrobial resistance (AMR) becomes pandemic and losses associated with it globally are enormous. Although discovery of new antimicrobials and making it available in the arsenal of clinicians is the best possible solution in tackling the current scenario of AMR, it is not happening for last two decades due to many factors. Focus of research is now diverted in development of non-antibiotic antimicrobials as an alternative therapeutic option. The major research activities and their potential application as alternative therapeutic agents are tried to narrate in the present article. The traditional approaches like antibiotic stewardship, increase of awareness, strengthen of diagnostic capabilities, improvement of vaccination schedules etc are not included in the article. With the advancement of new technologies including microbiology, molecular biology, biotechnology, genetic engineering, synthetic chemistry the scientists throughout the world could develop various natural as well as synthetic products as potential therapeutic candidates, which can replace the antibiotics in future. The article is focused on the major breakthrough on new or renewed technologies published in various parts of the world on non-antibiotic antimicrobial agents as potential alternative therapeutic approaches.
\end{abstract}

Key Words: Alternative approaches, AMR, Non-antibiotic antimicrobials

Antimicrobial resistance (AMR) is posing a serious threat globally and every year 7,00,000 patients die due to. It is also estimated that by 2050 , death toll may reach up to 10 million leading to reduction of GDP by minimum $2.5 \%$ (Ghosh et al., 2019). Tackling AMR amicably becomes a serious challenge and discovery of new antibiotics are not offering any positive directions. Due to this ambiguous situation, scientists have started thinking about alternatives to existing and conventional antibiotics as therapeutic options. As indicated in various existing literatures, various approaches were tried to find out possible alternatives to replace antibiotics as therapeutic options. Few of the major approaches with encouraging results are described here.

\section{Phage therapy}

Use of bacteriophages to treat infected animal and human subjects is much older than the antibiotic era. Bacteriophages propagate in bacteria through taking over the host cell machinery resulting in the synthesis of phage components and assembly of new phages within the infected bacteria. This method eventually causes bacterial lysis followed by release of phage progeny, which can initiate a

${ }^{\dagger}$ This paper was presented at the National Seminar on Antimicrobial resistance - A global menace: One health approach on March 07, 2020 at West Bengal University of Animal and Fishery Sciences, Kolkata, India organised by Indian Journal of Animal Health 
second infection cycle (Abedon et al., 2011). As bacteriophages are known to select between mixed populations of bacteria, this could be exploited to use them as an alternative but selective approach to target pathogenic bacteria over commensal bacteria. So far, many bacteriophages were approved by the FDA for treatment of different bacterial illness in human and animals (Ghosh et al., 2019). But certain issues related to bacteriophage therapy such as their high specificity towards a particular type of bacteria, development of immunity in the host body, pharmacokinetics and accumulation of endotoxins are major concern to be addressed (Kutter et al., 2010; Pelfrene et al., 2016).

Majority of the disadvantages with the natural bacteriophages were addressed with the advent of genetically modified/engineered phages. The engineered bacteriophages are capable to produce bacterial-biofilm-degrading enzymes upon infection (Lu and Collins, 2009). Therefore, both the biofilm and the bacteria that were embedded within the biofilm can be lysed. Engineered phages are also designed to overexpress lexA 3 that represses the bacterial SOS DNA repair system and make them more susceptible to bactericidal antibiotics (Chan et al., 2016). Phagemids are also tried to deliver small regulatory RNAs inside drug-resistant bacteria, which converts the resistant bacteria such as $P$. aeruginosa into susceptible one for conventional antibiotics (Edgar et al., 2012; Libis et al., 2014). Numerous engineered bacteriophages are currently used clinically or under clinical trials (Ghosh et al., 2019).

\section{Antimicrobial peptides (AMPs)}

AMPs and host defense peptides (HDPs) are the first line of defense produced by many multicellular organisms against invading pathogens (de Castro and Franco, 2015). Many AMPs/HDPs have been discovered and tried to be used as antibacterial agents, so far, with variable rate of success. In addition to that, they have diverse activities like anti-viral, anti-fungal, anti-plasmodial, anti-cancer, anti-protista, insecticidal and spermicidal including immunomodulation. AMPs are being used to selectively kill the bacteria without any activities against host cells. Although several AMPs are undergoing clinical trials, in vivo toxicity and difficult industrial scalability have hindered clinical translation of this class of alternative antimicrobial agents. In addition, reports of bacteria developing resistance against AMPs also do exist (Fosgerau and Hoffmann, 2015; Andersson et al., 2016; Mahlapuu, 2016; Zhang and Gallo, 2016; Greber and Dawgul, 2017).

\section{Synthetic mimics of antimicrobial peptides (SMAMPs)}

SMAMPs are genetically modified products developed to overcome the inherent disadvantages of AMPs (Engler et al., 2012). SMAMPs are modified and developed in such a way that they maintain all the basic properties of AMPs as well as can withstand protease activities, increasing penetration power and act as broadspectrum agents. Use of SMAMPs could also modify the MDR bacteria in such a way that they become re-sensitized to existing conventional antibiotics. Few of the SMAMPs are in advanced stage of clinical trials and are expected to be approved by the FDA as therapeutic agent against MDR bacteria. These compounds are synthetically simple, rapidly bactericidal and also effective against fungi, the malaria parasite and Ebola virus (Uppu et al., 2015; Czyzewski et al., 2016; Teyssières et al., 2016; Uppu and Haldar, 2016; Sang et al., 2017; Konai et al., 2018).

\section{Antibodies}

Antibodies are very useful alternatives for the treatment of bacterial infections due to its direct recognition and neutralization capacity of specific components of the pathogens. Numerous antibodies against various bacterial pathogens of human and animals are in various stages of clinical development and, in fact, some of them have already been approved by the FDA. But the major drawback of using antibodies for antibacterial therapy is the cost of the production and poor shelf life (Bebbington and Yarranton, 2008; Saylor et al., 2009). 


\section{Bacteriocins}

As self defense mechanism and in order to prevent competition and enhance survival, many bacterial species produce small AMPs termed as bacteriocins, which act against other bacteria within the population. These ribosomally synthesized peptides are classified into two groups; class I and class II. Their mechanism of action is similar to AMPs. So far, few of the potential bacteriocins are undergoing clinical trials at various stages. In fact, bacteriocins also suffer from the same problems as AMPs but their use in certain cases can offer more advantages like conventional antibiotics. Like AMPs, resistance against bacteriocins is slow but imminent (Cotter et al., 2013; Yang et al., 2014).

\section{Probiotics}

The gut microbiota of mammals comprises over 1000 microbial species, including bacteria and yeast, which play a crucial role in energy metabolism and immune function (Hamilton-Miller, 2003). Treatment of patient with antibiotics make serious disbalance in gut microbiota leads to secondary infections, like $C$. difficile induced colitis (CDI). Therefore, probiotics and prebiotics are indicated in the treatment of various gastrointestinal infections (Jia et al., 2008). Treatment with probiotics and prebiotics is advantageous over antibiotics as these agents are safe for long term consumption and do not cause side effects or allergies. There are many probiotics under clinical trials for the treatment of infections (Stier and Bischoff, 2016; Lewis and Pamer, 2017).

\section{Fecal transplant therapy (FTT)}

FTT is an attractive and safe alternative strategy, in which the microbiome from a healthy donor is being introduced into the diseased gut leading to curing bacterial infections or other cases involving gastrointestinal dysbiosis. The cure rate for patients undergoing colonoscopic FTT for recurrent CDI was recorded $90 \%$ and accordingly the FDA has approved the use of FTT for the treatment of patients suffering from CDI that is unresponsive to standard therapy. So far, it has shown highly promising result against MDR Enterobacteriaceae including E. coli, Salmonella, Klebsiella pneumoniae, Acinetobacter baumannii, MRSA and VRE (Aroniadis and Brandt, 2014).

\section{Predatory bacteria}

With the advent of science of microbiology, the use of predatory bacteria such as Bdellovibrio and like organisms (BALOs) has been considered as a highly promising alternative to antibiotics (Atterbury et al., 2011). These organisms multiply only upon entering their prey such as E. coli, Salmonella, Legionella, Pseudomonas as well as other pathogenic bacteria of human and animals without affecting the host cells. In addition to degradation of prey cells by lysing, BALOs can also penetrate into bacterial biofilm, giving them an advantage over conventional antibiotics (Kadouri et al., 2013). The lipopolysaccharide (LPS) of BALOs lacks the negatively charged phosphate group, resulting in reduced binding affinity to the LPS receptors in human immune cells and accordingly they exhibit minimum or no inflammatory response. The activities against wide range of bacteria, low immunogenicity, low toxicity, and negligible propensity to induce resistance make this bacterium a promising candidate for the treatment of infections (Sockett and Lambert, 2004).

\section{Innate defence regulatory peptides (IDRPs)} IDRPs are peptides with no antibacterial activity but with anti-endotoxin and immunomodulatory activities are proven to protect mice from succumbing to severe bacterial and malarial infections, without having any direct antimicrobial activity. They are a promising alternative to conventional antibiotics, and one of them has completed Phase I clinical trials for the treatment of bacterial infection (Achtman et al., 2012; Mansour et al., 2015; Hancock et al., 2016).

\section{Antibacterial oligonucleotides}

Gene silencing therapy has become popular for the treatment of numerous diseases including infectious diseases, where silencing of essential 
and resistance causing genes by the use of antisense oligonucleotides with sequences complimentary to the target mRNA was used. The oligonucleotides are modified to confer resistance to nuclease degradation as well as improved transport across the negatively charged bacterial membrane (Ayhan et al., 2016). They have shown potential antibacterial activity against a variety of bacteria such as E. coli, S. enterica and A. baumannii both in vitro and in vivo (Howard et al., 2017). The agents have also exhibited growth inhibition in the presence of sub-lethal concentrations of colistin and polymyxin B as well as restoration of the susceptibility of MRSA to oxacillin both in vitro and in vivo. This could also sensitize resistant staphylococci to other existing $\beta$-lactam antibiotics (cefatoxin, cephalothin, cefoperazone, cefoxitin and oxacillin) (Meng et al., 2015; Sully et al., 2017)

\section{CRISPR-Cas 9}

The CRISPR (clustered, regularly interspaced, short palindromic repeats)-Cas9 systems are key components of a bacterial immune system, in which 20 nt small RNA acts as a guide for Cas9 to remove foreign genetic elements like in plasmids and phages at speciûc sites (Bikard and Barrangou, 2017; de la Fuente-Nunez and Lu, 2017). Like in many other fields, the CRISPRCas9 system has been used in the field of antimicrobial therapeutics with a great level of success. Bacteriophages were used to deliver the

\section{REFERENCES}

Abedon ST, Kuhl SJ, Blasdel BG and Kutter EM, 2011. Phage treatment of human infections. Bacteriophage, 1: 66-85

Achtman AH, Pilat S, Law CW, Lynn DJ, Janot L et al., 2012. Effective adjunctive therapy by an innate defense regulatory peptide in a preclinical model of severe malaria. Sci Transl Med, 4:135ra64

Andersson DI, Hughes D and Kubicek-Sutherland JZ, 2016. Mechanisms and consequences of bacterial resistance to antimicrobial peptides. Drug Resist Updat, 26: 43-57
CRISPR-Cas 9 system to target multidrugresistant bacteria to make them susceptible (Doudna and Charpentier, 2014; Goren et al., 2017). The CRISPR-Cas9 system was also successfully tried to selectively kill virulent, but not avirulent, strains of $S$. aureus. Overall, CRISPR-Cas9 based systems offer an excellent alternative to antibiotics but their industrial scalability remains a question (Yosef et al., 2015; Wang et al., 2016).

In conclusion, it may be mentioned that numerous alternatives to conventional antibiotics have been developed so far to combat antimicrobial resistance and treat bacterial infections. Some of the approaches have shown encouraging level of progress, whereas others are still at the laboratory stage. Majority of the approaches are strain or species speciûc in contrast to the broad spectrum activities of conventional antibiotics and therefore, multiple therapeutics require to be practicised for the treatment of different infections. Although some progresses haves been made but the current status indicates that alternative approaches can only partially replace antibiotics. Recent progress in genetic engineering offers significant possibilities for further improvement. Future studies must investigate the efficacy of combining conventional antibiotics with one of these alternative therapies to fully assess their potential. The field is in its nascent stage and further research must be focused on development of next generation therapeutic agents.

Aroniadis OC and Brandt LJ, 2014. Intestinal microbiota and the efficacy of fecal microbiota transplantation in gastrointestinal disease. Gastroenterol Hepatol, 10: 230-237

Atterbury RJ, Hobley L, Till R, Lambert C, Capeness MJ et al., 2011. Effects of orally administered Bdellovibrio bacteriovorus on the well-being and Salmonella colonization of young chicks. Appl Environ Microbiol, 77: 5794-5803

Ayhan DH, Tamer YT, Akbar M, Bailey SM, Wong M et al., 2016. Sequence-specific targeting of 
bacterial resistance genes increases antibiotic efficacy. PLoS Biol. 14: e1002552

Bebbington C and Yarranton G, 2008. Antibodies for the treatment of bacterial infections: current experience and future prospects. Curr Opin Biotechnol, 19: 613-619

Bikard D and Barrangou R, 2017. Using CRISPR-Cas systems as antimicrobials. Curr Opin Microbiol, 37: $155-160$

Chan BK, Sistrom M, Wertz JE, Kortright KE, Narayan D et al., 2016. Phage selection restores antibiotic sensitivity in MDR Pseudomonas aeruginosa. Sci Rep, 6: 26717

Cotter PD, Ross RP and Hill C, 2013. Bacteriocins - a viable alternative to antibiotics? Nat Rev Microbiol, 11: 95-105

Czyzewski AM, Jenssen H, Fjell CD, Waldbrook M, Chongsiriwatana NP et al., 2016. In vivo, in vitro, and in silico characterization of peptoides as antimicrobial agents. PLoS One 11, e0135961

de la Fuente-Nunez C and Lu TK, 2017. CRISPR-Cas9 technology: applications in genome engineering, development of sequence-speciûc antimicrobials, and future prospects. Integr Biol, 9: 109-122

de Castro AP and Franco OL, 2015. Modifying natural antimicrobial peptides to generate bioinspired antibiotics and devices. Future Med Chem, 7: 413-415

Doudna JA and Charpentier E, 2014. Genome editing. The new frontier of genome engineering with CRISPR-Cas9. Science, 346: 1258096

Edgar R, Friedman N, Molshanski-Mor S and Qimron U, 2012. Reversing bacterial resistance to antibiotics by phage-mediated delivery of dominant sensitive genes. Appl Environ Microbiol, 78: 744-751

Engler AC, Molshanski-Mor S and Qimron U, 2012. Emerging trends in macromolecular antimicrobials to fight multi drug resistant infections. Nano Today, 7: 201-222
Fosgerau K and Hoffmann T, 2015. Peptide therapeutics: current status and future directions. Drug Discov Today, 20: 122-128

Ghosh C, Sarkar P, Issa R and Haldar J, 2019. Alternatives to conventional antibiotics in the era of antimicrobial resistance. Trends Microbiol, 27: 323-338

Goren M, Yosef I and Qimron U, 2017. Sensitizing pathogens to antibiotics using the CRISPR-Cas system. Drug Resist Updat, 30: 1-6

Greber KE and Dawgul M, 2017. Antimicrobial peptides under clinical trials. Curr Top Med Chem, 17: 620-628

Hamilton-Miller JM, 2003. The role of probiotics in the treatment and prevention of Helicobacter pylori infection. Int $\mathrm{J}$ Antimicrob Agents, 22: 360-366

Hancock RE, Haney EF and Gill EE, 2016. The immunology of host defence peptides: beyond antimicrobial activity. Nat Rev Immunol, 16: 321-334

Howard JJ, Sturge CR, Moustafa DA, Daly SM, Marshall-Batty KR et al., 2017. Inhibition of Pseudomonas aeruginosa by peptideconjugated phosphorodiamidate morpholino oligomers. Antimicrob Agents Chemother, 61: e01938-16

Jia W, Li H, Zhao L and Nicholson JK, 2008. Gut microbiota: a potential new territory for drug targeting. Nat Rev Drug Discov, 7: 123-129

Kadouri DE, To K, Shanks RM and Doi Y, 2013. Predatory bacteria: a potential ally against multidrug-resistant gram-negative pathogens. PLoS One 8: e63397

Konai MM, Bhattacharjee B, Ghosh S and Haldar J, 2018. Recent progress in polymer research to tackle infections and antimicrobial resistance. Biomacromolecules, 19: 1888-1917

Kutter E, De Vos D, Gvasalia G, Alavidze Z, Gogokhia L et al., 2010. Phage therapy in clinical practice: treatment of human infections. Curr Pharm Biotechnol, 11: 69-86 
Lewis BB and Pamer EG, 2017. Microbiota therapy for Clostridium difûcile and antibiotic resistant enteric infections. Annu Rev Microbiol, 71: $157-178$

Libis VK, Bernheim AG, Basier C, Jaramillo-Riveri S, Deyell M et al., 2014. Silencing of antibiotic resistance in $E$. coli with engineered phage bearing small regulatory RNAs. ACS Synth Biol, 3: $1003-1006$

Lu TK and Collins JJ, 2009. Engineered bacteriophage targeting gene networks as adjuvants for antibiotic therapy. Proc Natl Acad Sci USA, 106: 4629-4634

Mahlapuu M, 2016. Antimicrobial peptides: an emerging category of therapeutic agents. Front Cell Infect Microbiol, 6: 194-199

Mansour SC, de la Fuente-Núñez C and Hancock RE, 2015. Peptide IDR-1018: modulating the immune system and targeting bacterial bioûlms to treat antibiotic-resistant bacterial infections. J Pept Sci, 21: 323-329

Meng J, He G, Wang H, Jia M, Ma X et al.,2015. Reversion of antibiotic resistance by inhibiting $m e c A$ in clinical methicillin resistant staphylococci by antisence phosphorothioate oligonuleotide. J Antibiot, 68: 158-164

Pelfrene E, Willebrand E, Cavaleiro SA, Sebris Z and Cavaleri M, 2016. Bacteriophage therapy: a regulatory perspective. J Antimicrob Chemother, 71: 2071-2074

Sang P, Shi Y, Teng P, Cao A, Xu H et al., 2017. Antimicrobial AA peptides. Curr Top Med Chem, 17: 1266-1279

Saylor C, Dadachova E and Casadevall A, 2009. Monoclonal antibody-based therapies for microbial diseases. Vaccine 27: G38-G46.

Sockett RE and Lambert C, 2004. Bdellovibrio as therapeutic agents: a predatory renaissance? Nat Rev Microbiol, 2: 669-675
Stier H and Bischoff SC, 2016. Inûuence of Saccharomyces boulardii CNCM I-745on the gut-associated immune system. Clin Exp Gastroenterol, 9: 269-279

Sully EK, Geller BL, Li L, Moody CM, Bailey SM et al., 2017. Peptide-conjugated phosphorodiamidate morpholino oligomer (PPMO) restores carbapenem susceptibility to NDM-1-positive pathogens in vitro and in vivo. J Antimicrob Chemother, 72: 782790

Teyssières E, Corre JP, Antunes S, Rougeot C, Dugave C et al., 2016. Proteolytically stable foldamer mimics of host-defense peptides with protective activities in a murine model of bacterial infection. J Med Chem, 59: 8221-8232

Uppu DS and Haldar J, 2016. Lipopolysaccharide neutralization by cationic amphiphilic polymers through pseudoaggregate formation. Biomacromolecules, 17: 862-873

Uppu DS, Manjunath GB, Yarlagadda V, Kaviyil JE, Ravikumar R et al., 2015. Membrane active macromolecules resensitize NDM-1 gramnegative clinical isolates to tetracycline antibiotics. PLoS One, 10: e0119422

Wang H, La Russa M and Qi LS et al., 2016. CRISPR/ Cas9 in genome editing and beyond. Annu Rev Biochem, 85: 227-264

Yang SC, Lin CH, Sung CT and Fang JY, 2014. Antibacterial activities of bacteriocins: application in foods and pharmaceuticals. Front Microbiol, 5: 241-249

Yosef I, Manor M, Kiro R and Qimron U, 2015. Temperate and lytic bacteriophages programmed to sensitize and kill antibioticresistant bacteria. Proc Natl Acad Sci USA, 112: 7267-7272

Zhang LJ and Gallo RL, 2016. Antimicrobial peptides. Curr Biol, 26: R14-R19

Received-07.03.2020, Accepted-28.04.2020, Published-01.06.2020

[The article was presented in the National Seminar on Antimicrobial resistance - A global menace: One health approach on March 07, 2020 at West Bengal University of Animal \& Fishery Sciences, Kolkata, West Bengal organised by Indian Journal of Animal Health ] 